\title{
Strategy guidelines for the Croatian petroleum industry based on geopolitical risk assessment
}

\author{
D. Karasalihovic \\ Department of Petroleum Engineering, \\ Faculty of Mining Geology and Petroleum Engineering, Croatia
}

\begin{abstract}
Over the last 50 years 79 oil and gas fields were discovered in Croatia with more than 460 million $\mathrm{m}^{3}$ of oil equivalent (OE), which sets the petroleum industry as a very important part of the Croatian economy. Proven oil and gas reserves were estimated to be 198 million $\mathrm{m}^{3} \mathrm{OE}$. In the same period Croatia produced more than 155 million $\mathrm{m}^{3} \mathrm{OE}$. Today there are 43 oil and 13 gas fields. Until the 1970s domestic oil production was sufficient for satisfying the entire Croatian demand for liquid fuels. The fact that current domestic production meets only $20 \%$ of oil and around $50 \%$ of natural gas demand, implies the necessity for acceptable strategy implementation that will perceive domestic market demands along with global market conditions. Since one company represents the largest part of the Croatian petroleum industry, the basic problem represents compliance of small and medium petroleum companies to heavy business conditions in the global market. This is a consequence of petroleum companies' high sensibility to geopolitical risks. Therefore, the precise evaluation of geopolitical risks in time and the assessment of the impact of the creation of a company business strategy could be crucial for the entire Croatian petroleum industry. The Croatian petroleum industry expressly needs business expansion in the markets of neighbouring countries and recovering oil and natural gas reserves from areas with a higher potential in reserves exploration but also with higher political instabilities. Also, it is pressurized by the necessity of business rationalization and the improvement of profitability. Therefore, geopolitical risk assessment is of great importance for the creation of strategic guidelines that should show a way of meeting domestic hydrocarbon consumption along with achieving a desirable business position especially in the regional market.
\end{abstract}

Keywords: Croatian petroleum industry, strategic planning, risks assessment, geopolitical risk. 


\section{Introduction}

Croatian Energy consumption in 2004 was in total 412 PJ and since 1992 there was constant increase in consumption. Annual consumption rate in last few years averaged around $2.2 \%$. The liquid fuels have the highest share of $44 \%$, while the natural gas share was around $25 \%$. The Croatian energy consumption per capita is only $55 \%$ of EU15 average. Energy production from primary energy sources in 2004 was in total 204.4 PJ with $1.9 \%$ of average annual increase since 1999. In energy structure in 2004 the highest share of $38 \%$ was in natural gas production, $38 \%$ in hydropower and $21 \%$ in crude oil production. Therefore, the primary energy production rate was lower than rate of total energy consumption rate and much lower than, rate of direct energy consumption. These issues represent strategic importance of petroleum industry as part of integral Croatian economy sector [1].

\section{Croatian petroleum industry}

Croatian petroleum industry is represented by one national oil company, which is mainly state owned in strategic partnership with Hungarian petroleum company MOL. INA is vertically integrated oil and gas company operating in oil and gas exploration and production, refining and marketing of oil products. Its subsidiaries are engaged in LPG business, natural gas transportation and providing integrated oilfield services. INA is a medium-sized European oil company and a significant regional player. The mother company INA Group consists of a few subsidiaries with main activities in exploration and production of oil and natural gas in Croatia and abroad, natural gas import and marketing of domestic and imported gas for industry and gas distributors, refining, petroleum product marketing in country and abroad, marketing of crude oil, diesel and gasoline, services including drilling, over haul and other activities during hydrocarbon exploration and production onshore and off shore, pipeline construction, process facilities construction and maintenance, petroleum lubricants production and marketing and LNG production and marketing.

Concerning company size, market dimension, dispersion and range of business activities, INA represents typical national company on middle and southeast European market. The fact that INA is national company refers to mostly state ownership, and INA has the superior position in oil product trade at domestic market, highly above $50 \%$, with the smaller share at the neighbour markets at the same time.

Strategic goal for Croatian petroleum industry represents annual production of minimum 4 million $\mathrm{m}^{3} \mathrm{OE}$ (oil equivalent) and $100 \%$ reserve replacement ratio which is possible only along with development and exploration activities of domestic and foreign exploration areas. Although Croatian areas with commercial discoveries are highly explored, it is important to stress justifiability of further investment into development of new areas, regarding necessity for hydrocarbon reserves replacement, but also investment into brown fields. This is 
important considering constant increase of oil prices. Therefore, reserve replacement should be included into business strategy of company whose business success is based on exploration and development of oil and natural gas fields. The minimum annual reserves amount should equal annual production when business performances are measured by reserves replacement ratio (Croatian Ministry of Economy, Labour and Entrepreneurship [2]).

Based on production and consumption data, energy structure and hydrocarbon share have been predicted for the future 20 years [3]. In addition hydrocarbon import projections have been made for the future period (figures $1-4$ ).

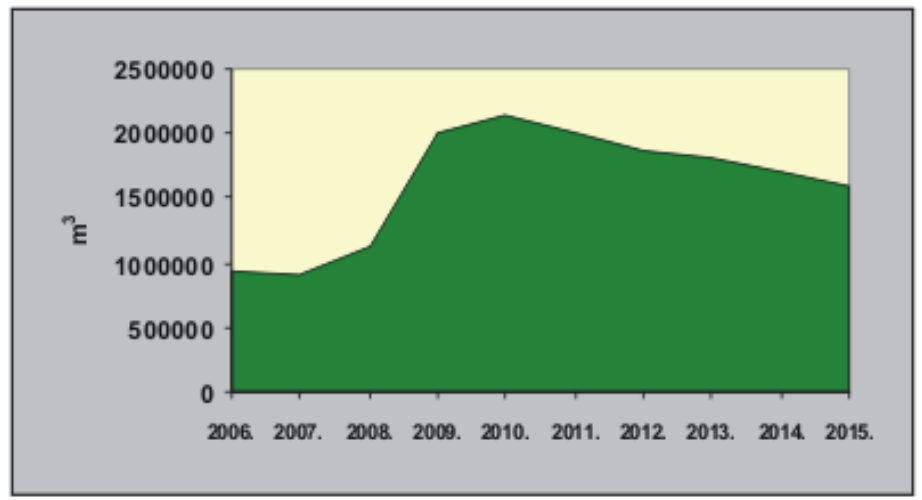

Figure 1: Prediction of oil and condensate production in Croatia in period 2005-2015.

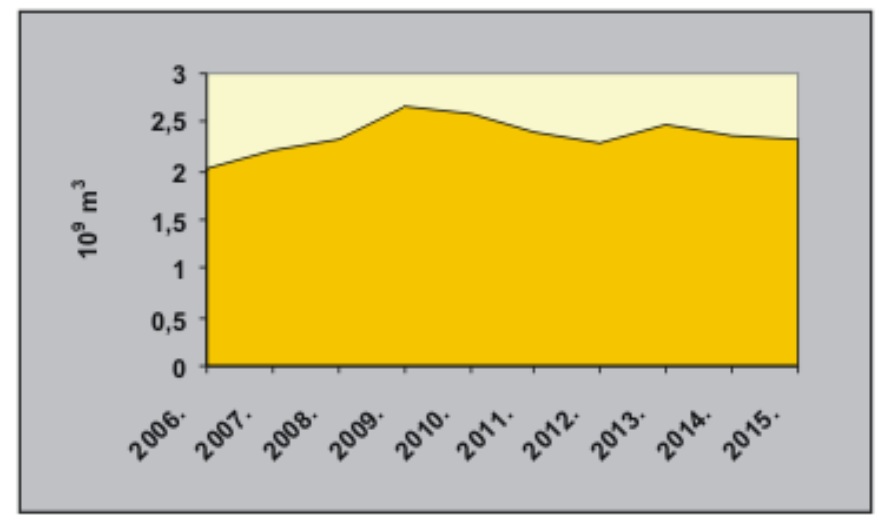

Figure 2: Prediction of natural gas production in Croatia in period 2005-2015. 


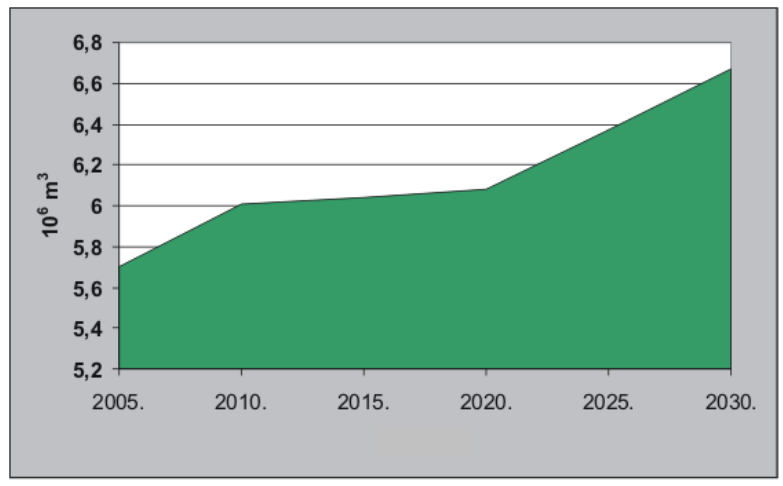

Figure 3: Prediction of liquid fuels consumption in Croatia in period 2005-2030.

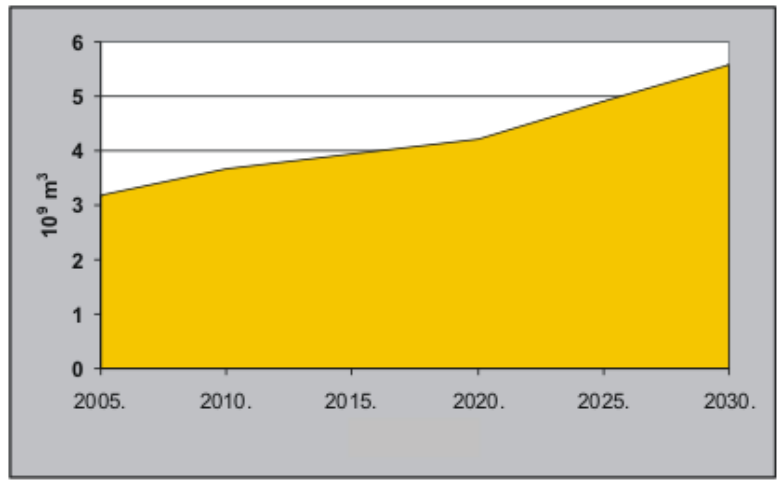

Figure 4: Prediction of natural gas consumption in Croatia in period 2005-2030.

Shown data should be included into supply directions concerning national energy demand. Besides, it is necessary to include consumption increase patterns into strategy guidelines with review of current and planned supply directions for oil and natural gas, concerning Croatian geostrategic position in European supply network, along with its political aspect. It should be emphasized that petroleum industry mid-term investments are made for sufficiency insurance reasons, but also for supply safety reasons. Concerning GDP growth, which was 4-5\% annually between 2000 and 2005, the same expectations are that GDP could come to $€ 7000$ per capita. Consequently future economic growth and market development will be depending on energy sufficiency insurance. Predicted energy demand requires significant energy projects planning (Beck [4]). 


\section{Strategic planning and risk assessment in petroleum industry}

Oil companies were the first in world in implementation of long-term strategy planning. During history oil companies were developed as capital intensive with need for very huge investments. Relatively high exploration risks resulted in business practice, which includes mainly or fully proper financing of oil and natural gas project (Seba [5]).

The petroleum exploration, production and refining industry is characterized as a "risk business". The usual reference is to the geological risk of drilling nonproductive wells. With the growing volatility of oil and gas prices, financial risk becomes increasingly important factor, which includes also geopolitical risks. The traditional method of coping with risk has been through methods such as diversification, sheer size and vertical integration of oil and gas production and downstream refining and marketing. There are many varieties of risk including technical, economic and political risks. Based on analysis of oil prices and oil and natural gas reserves distribution in the world the category of geopolitical risk should be introduced into enterprise risk management. Furthermore, it is common practice to weight risk mathematically in order to obtain a proper overall approximation of risk impact, but risks are generally considered as three broad categories namely, technical, economical and political.

Economic risk covers a very broad range of potential situations. The prime economic concerns involve drilling and operating costs, inflationary effects and interest rates, as well as product prices and demand.

Technical risks involve the operational nature of the project and may include engineering capability and experience, hydrocarbon volumes that actually exist underground, producing rates and ultimate recovery.

Political risk can be defined as any political change that alters the expected outcome and value of a given economic action by changing the probability of achieving business objectives. Politics influences how markets operate. Often the most unpredictable economic events are political in origin, the result of flagging political willingness or capacity to maintain a consistent and predictable economic environment. Furthermore, political risks involve uncertainty arising from possible changes in the policies of regulatory authorities and degree to which such changes may affect the project revenues. Regulatory considerations can be subdivided into fiscal and non-fiscal considerations. The fiscal aspects primarily include continuity in the levels of local currencies, changes in levels of customs duties on imported equipment and supplies and possible imposition of locally denominated prices for the production. Non-fiscal political risks may relate to possible interruptions by regulatory authorities over environmental meters, disagreements over hiring or firing of local personnel, determinations of commerciality or outright nationalization. Meters such as the provisions for transfer of operator ship to the national oil companies and the potential for political unrest in the host country also fall under this category (McAfee [6]).

Geopolitical risks is the new category that implies uneven distribution of oil and gas reserves and their situation in regions without strong control of western 
industrialized countries which are the main oil and gas consumers. Furthermore, geopolitical risks involve international stability and possibility of terrorist attacks, international sanctions, production output blackmails, fears of shortages but also wide range of other geopolitical issues that can directly impact oil and gas supply, demand and prices and consequently impact companies business performances. This category also relate to unavailability of exploration areas with higher discovery potential to small and medium petroleum companies without internationally strong political backgrounds. There is also different probability for e.g. medium company originated from USA or Croatia for exploration concession gaining in Iraq.

Therefore, risk assessment as important part of strategic planning represents a continual process and way of doing business that helps organizations take more proactive approach to identifying and eliminating exposures and comprehensively blocking attacks while planning and implementing business strategies. It is specifically designed to help define critical assets, assess threats and vulnerabilities, comprehensively block attacks and implement the security measures required to minimize risks.

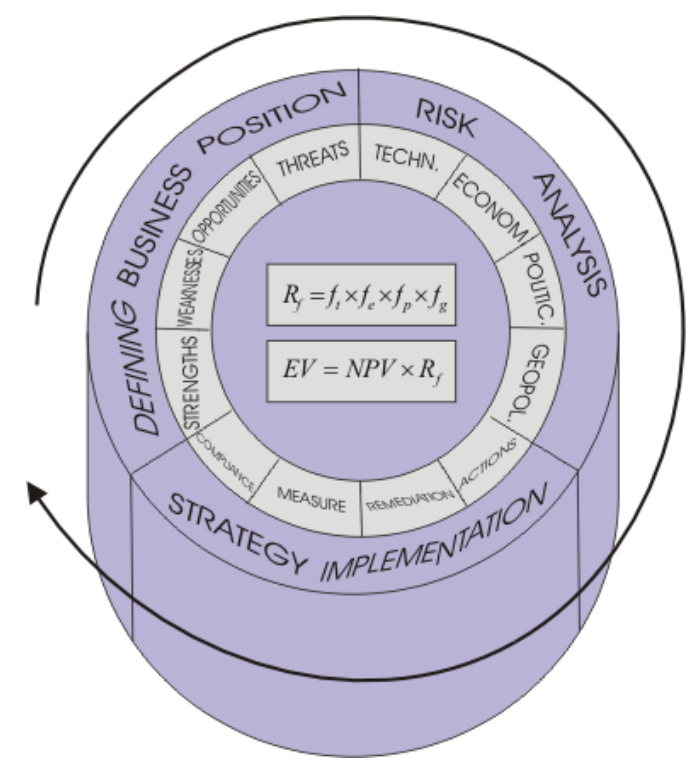

Figure 5: Strategic planning process with geopolitical risks assessment.

\subsection{Strategic planning with introduction of geopolitical risk into risk assessment}

Based on risk assessment, including all types of risk, management should answer some key questions like: What policies have company established, what assets does company have, and how important are those assets to business goals? What 
risk does company face given the vulnerabilities on business critical assets, the threats that could exploit those vulnerabilities, and the risk company is willing to accept? What can management block while planning and implementing strategies based on risk assessment? What can be measured and how to check compliance against original policies to determine the progress making with implemented strategy? (EurasiaGroup [7])

Introduction of new category of geopolitical risks represents incorporation of recommendations that enhance a company's internal capacity to manage global risks, as well as to identify and capitalize on unexploited opportunities. Geopolitical risk assessment helps business leaders to understand the nature of global political risk and its impact on their international investments, and to seize the opportunities it affords. Evaluating company's exposure to risky political events, and assessing their impact, should be key components of any company's strategy (Figure 5).

Conducting a risk analysis turns uncertainty into calculable risk. Because businesses are often affected by political decisions in the countries where they operate, at home and abroad, all companies factor the political environment into planning scenarios. However, geopolitical risk can seem so amorphous that many business leaders lack a framework for evaluating their exposure.

Since security concerns rise, understanding of geopolitical risk becomes increasingly important as terrorism and conflicts in the Middle East and Northeast Asia generate new security policy concerns. The United States is now a major driver of international risk, and United States Government new willingness to pre-empt threats to American security and national interests has changed risk calculations everywhere. Companies must identify whether domestic, regional, or global security threats will affect the cost of doing business. How will those costs compare with doing business elsewhere?

Also energy dependence shows that all energy-importing countries share an interest in diversifying their oil supply, both away from an increasingly unstable Middle East and toward alternative sources of fuel. Common objectives in energy coordination include increasing efficiencies in energy transfer and use and promoting infrastructure efficiencies that avoid bottlenecks and diminish regional variation in energy costs. Understanding how local, regional, and global energy concerns can affect investment decisions requires country-specific knowledge of how political actors will respond to energy shortages.

Furthermore, geopolitical risks include terrorism, energy-price volatility, political instability in the Middle East, weapons proliferation, Northeast Asian security instability, and the role of India and China in the global marketplace. Geopolitical risk analysis informs company how previously mentioned issues directly affect financial markets and long-term foreign investments.

According to PricewaterhouseCoopers and Eurasia Group consultants, political stability is linked to economic vitality. Looking at a map highlighting many of the world's developing nations, the countries with the strongest economies also tend to be the most politically stable (figure 6). This is true even where political stability is a result of a strong, yet market-oriented, autocratic regime (PricewaterhouseCoopers [8]). 
By their nature, emerging markets are places where political decisions have a greater effect on markets than economic trends, thus diminishing the value of employing economic guideposts to investment decisions. In politics, risks are more difficult to identify, to measure, and to hedge. Consequently, investors from petroleum industries are extremely concerned with the risks of nationalization, weak legal systems, corruption, and regulatory stability.

By considering political-science theories and financial markets expertise these, business leaders can adjust strategy to deflect adverse affects on operations or take advantage of opportunities. Corporations and governments concerned with the impact of an international issues, such as terrorism or energy supply, need systematic analysis to complement country-specific coverage. By integrating global political risk into the company's strategy, executives can better understand the global exposures and balance the company's risk appetite against achievement of corporate objectives.

The geopolitical risk assessment must have systematic approach for understanding and anticipating how current and future political events could materially affect a company's organization, and thereby helps the company better manage its international exposures.

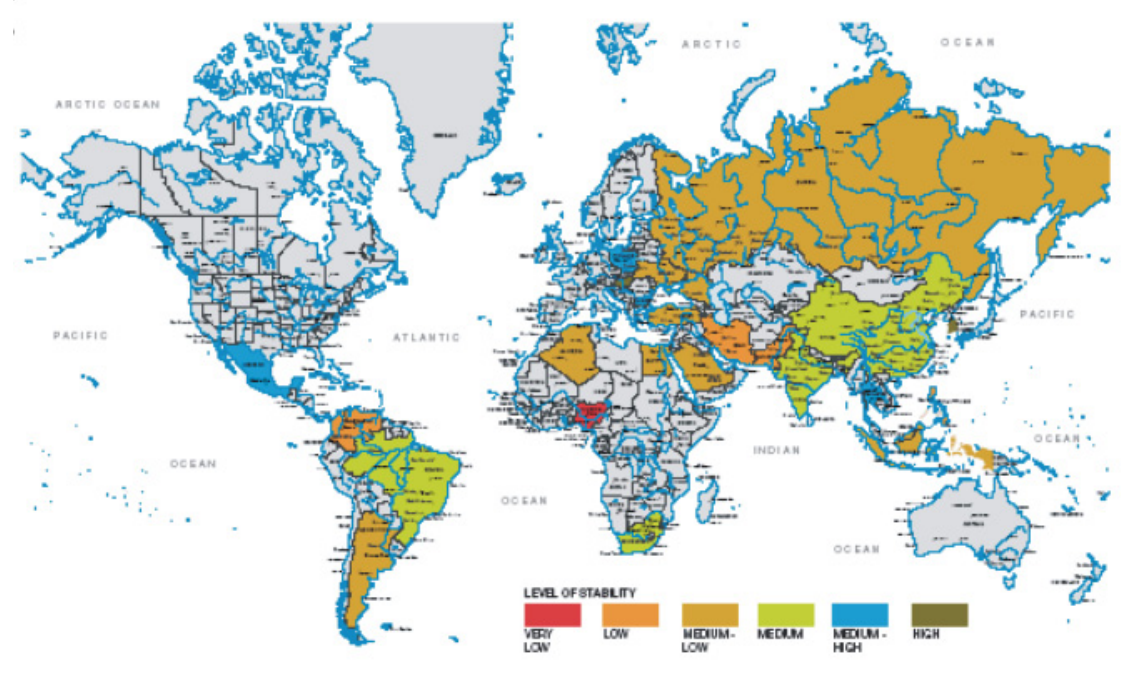

Figure 6: Level of stability in the world according to PricewaterhouseCoopers.

\section{Defining strategy guidelines for Croatian petroleum industry}

Process of defining strategy guidelines for business strategy of INA should start with enterprise risk management, process that has entered the mainstream of 
corporate consciousness over the past decade. Corporations and financial institutions globally have spent a great deal of money to develop and implement systems and processes to assess and manage risk more effectively.

Geopolitical analysis as part of risk assessment should give standpoints of INA's current and future international investments, global supply chains, and key foreign commercial relationships. These issues should be related to global trends, macro-level country risks, and petroleum industry-specific risks to create a comprehensive picture of risk exposure. Second stage of strategy description should include impact analysis that will assess the INA's vulnerability to risks and the potential economic and strategic impacts of risks on company costs and revenues. Furthermore, it is necessary to test qualitative and quantitative risk scenarios and strategic responses. The last strategy faze will give recommendations that will include a plan for mitigating identified risks, pursuing potential opportunities, or seeking alternative strategies with ongoing monitoring of political risks and business compliance issues.

The strategic importance of Croatian national petroleum company and its business rationalization are the reason for implementation of geopolitical risk assessment into company strategy guidelines with the main object of meeting domestic consumption along with achieving desirable business position on regional market.

Therefore, Strategy Guidelines should include further issues:

- Safe supply and production of oil and natural gas,

- Supply directions diversification and adoption of new technologies for exploration and production of hydrocarbons,

- Affordable oil and natural gas prices,

- Increase of energy efficiency,

- Increase of natural gas share in total energy consumption,

- Environmental protection,

- Easy access to regional and European energy markets,

- Development of a clean and efficient exploration and production technologies,

The basic principles of INA's enterprise strategy guidelines for achieving long-term sustainable development of Croatian petroleum industry include implicitly of:

- Increase of income and maximization of the company profit,

- Realizing desirable business performances,

- Achieving strong company competitiveness and export orientation,

- Systematic opening and access to international business environment,

- Further exploration and production of domestic hydrocarbon reserves,

- Firming company position in national social and economic environment,

- Self-financing and decrease of company indebtedness,

- Reserve replacement and investment into new exploration and production technologies,

- Acquisition of foreign concessions,

- Achieving strong position among international petroleum players. 


\section{Conclusion}

In past, business strategy of INA was related to wider market which included the whole area of former Yugoslavia, afterwards it was only oriented to domicile market, and now in present circumstances INA is re-entering neighbour markets. Furthermore, INA's business strategy involves characteristics, typical for any other transitional European company. INA has accomplished business strategy modification with partial restructuring for business improvement under market principles and has started privatisation process. In mentioned circumstances INA's business strategy becomes characteristic for medium-size petroleum company with the careful adoption of global oil market influences, introduction into global oil market through assurance of foreign oil and natural gas exploration and production projects, and finally defending and firming of leading position in refining and marketing of petroleum products at domicile market.

\section{References}

[1] www.eihp.hr

[2] Croatian Ministry of Economy, Labour and Entrepreneurship; Energy in Croatia 2003, Croatia, 2003.

[3] www.mingorp.hr

[4] Beck, R.J., Worldwide Petroleum Industry Outlook, $20^{\text {th }}$ Edition, Penwell, US, 2004.

[5] Seba, R.D., Economics of Worldwide Petroleum Production, OGCI Publications, Tulsa, Oklahoma, US, 1998.

[6] Minimizing Business Risk; McAfee, www.mcafee.com

[7] www.eurasiagroup.net

[8] www.pwc.com 